\title{
THE NETWORK OF SMART SENSORS FOR INDOOR Air QUALITY MONITORING
}

\author{
Adnan Masic*, Goran Kepnik, Jasmin Bektesevic, \\ Midhat Mehuljic,Isad Saric \& Vahidin Hadziabdic
}
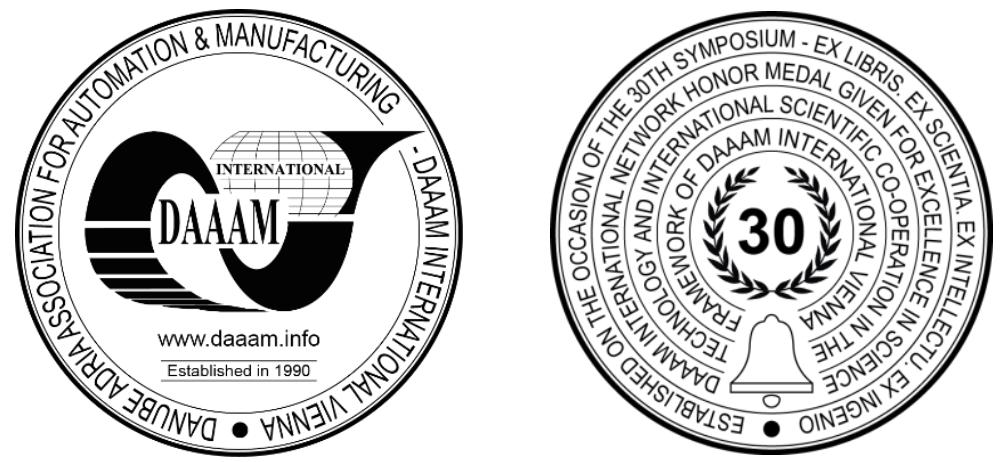

This Publication has to be referred as: Masic, A[dnan]; Kepnik, G[oran]; Bektesevic, J[asmin]; Mehuljic, M[idhat]; Saric, I[sad] \& Haziabdic, V[ahidin] (2020). The Network of Smart Sensors for Indoor Air Quality Monitoring, Proceedings of the 31st DAAAM International Symposium, pp.0232-0235, B. Katalinic (Ed.), Published by DAAAM International, ISBN 978-3-902734-29-7, ISSN 1726-9679, Vienna, Austria DOI: $10.2507 / 31$ st.daaam.proceedings.032

\begin{abstract}
A novel method for indoor air quality monitoring is presented in this paper. It is based on the network of smart sensors permanently connected to the cloud. The prototype system, consisting of 10 smart sensors is evaluated in laboratory and real use. Each smart sensor was able to measure air temperature, relative humidity, particulate matter concentration, and carbon dioxide concentration. The cloud-based architecture of the system is explained, followed by the calibration method and real scenario results. The system proved to be suitable for real-time monitoring of indoor air quality parameters for large buildings.
\end{abstract}

Keywords: Indoor air quality; Sensor network; Particulate matter; Carbon dioxide; Low-cost sensors.

\section{Introduction}

Issue of air pollution attracted a lot of attention in scientific community. However, the problem of indoor air quality is often neglected. Considering the time that we spend indoors, it is very important to address this issue. When we analyse the air quality, we usually measure concentrations of major pollutants, such se the particulate matter (PM). A particularly important parameter for indoor air quality is the carbon dioxide $\left(\mathrm{CO}_{2}\right)$. Measurement of concentration of carbon dioxide $\left(\mathrm{CO}_{2}\right)$ in the air is very important in many areas: from food production to the indoor air quality assessment and control [1], [2]. In the era of massive automatization and IoT (Internet of Things), having a good technique for $\mathrm{CO}_{2}$ determination is a necessity [3]. Furthermore, to assess the level of comfort in buildings, we need to measure the air temperature and relative humidity. Low-cost sensors offer great potential to cover large structures if used in network.

However, they must be calibrated if we require reliable readings. Calibration of $\mathrm{CO}_{2}$ sensors is usually performed at factory, which may be good enough for some applications. But in many cases professional (and potentially expensive) individual sensor calibration is required [4], [5]. The same applies to temperature, humidity and PM sensors. In this paper we present a novel method to build, calibrate and use the network of low-cost sensors for real-time indoor air quality monitoring. The research question is: to what extent this technology can be used for realistic scenarios in large buildings, occupied by many people working simultaneously? 


\section{The network of smart sensors and calibration procedure}

The design of the proposed network is shown in Fig. 1. (left). The concept of cloud is used to connect multiple elements: smart sensors, server, database and clients. All individual components of this system are developed in-house. Highly optimized C++ programs run on each smart sensor and server, which can be small computer such as Raspberry Pi or any other server running Linux. Sensors use TCP protocol to communicate with the server, which stores the data in PostgreSQL database. Users can access the real-time data using an SQL client, web page or mobile application.

Two important features of our cloud system are: quality of service $(\mathrm{Q} O S)$, which prevents data loss if there are temporary problems with internet connection and advanced calibration algorithm. The calibration procedure for particulate matter (PM) is explained in our previous work [6], [7], for toxic gases and $\mathrm{CO}_{2}$ in [8], [9], and for temperature and humidity in [10]. Fig. 1. (right) shows the batch of 10 smart sensors undergoing the calibration procedure in our laboratory.

\section{CLIENTS}
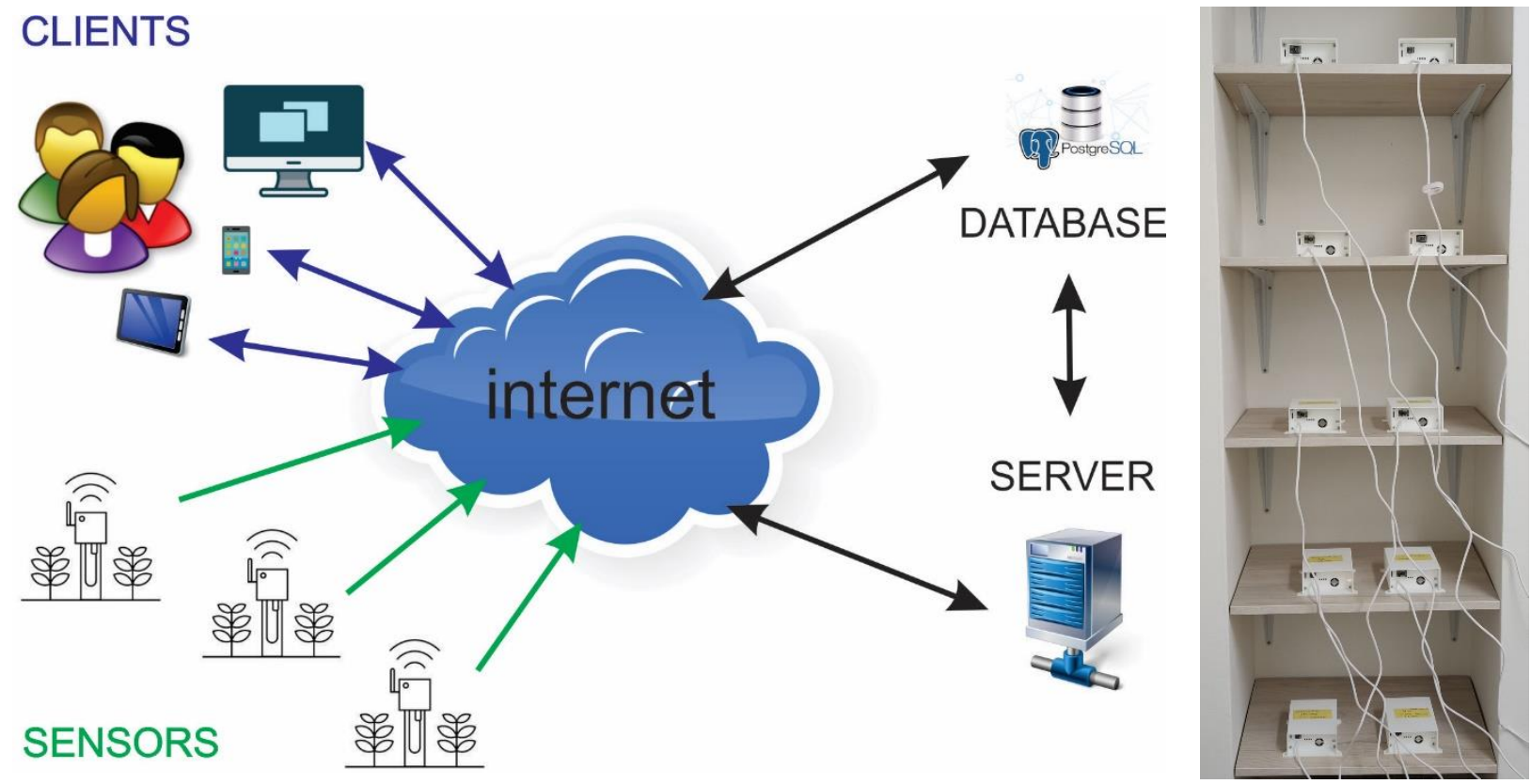

Fig. 1. Design of the network and calibration procedure

Specifications for each smart sensor are given in Table 1.

\begin{tabular}{|c|c|c|}
\hline Quantity & Range & Accuracy \\
\hline $\mathrm{PM}_{1}, \mathrm{PM}_{2.5}$ and $\mathrm{PM}_{10}$ & $0-999 \mu \mathrm{g} / \mathrm{m}^{3}$ & $10 \%$ \\
\hline $\mathrm{CO}_{2}$ & $0-5000 \mathrm{ppm}$ & $50 \mathrm{ppm}+5 \%$ \\
\hline Air temperature & $-40-90{ }^{0} \mathrm{C}$ & $0.3^{0} \mathrm{C}$ \\
\hline Air humidity & $0-100 \% \mathrm{rh}$ & $2 \% \mathrm{rh}$ \\
\hline
\end{tabular}

Table 1. Sensor specifications

\section{Results}

This set of 10 calibrated smart sensors is used for trial measurements from 17/OCT/2020 till 30/SEP/2020 in a modern business building. One sensor was placed outside in the courtyard while other sensors were distributed to offices and hallways. Fig. 2. Shows the results. Selected offices are shown in the graphs, due to the limited space in chart area. Air quality was good in this period. Pollution by particles PM2.5 was mostly below threshold of $12 \mu \mathrm{g} / \mathrm{m}^{3}$ (good air quality), with occasional increase to the area of moderate air quality. Carbon dioxide levels well below 1000 ppm indicate excellent ventilation system in the building. During the weekends, daily average $\mathrm{CO}_{2}$ levels were minimal, which is expected due to absence of the employees.

Temperature and humidity were well regulated, providing good thermal comfort most of the time. Comfortable humidity levels between $40 \%$ and $50 \%$ were observed. During several days of August, high indoor temperatures were registered, reducing the thermal comfort for occupants. 
PM2.5 daily average values

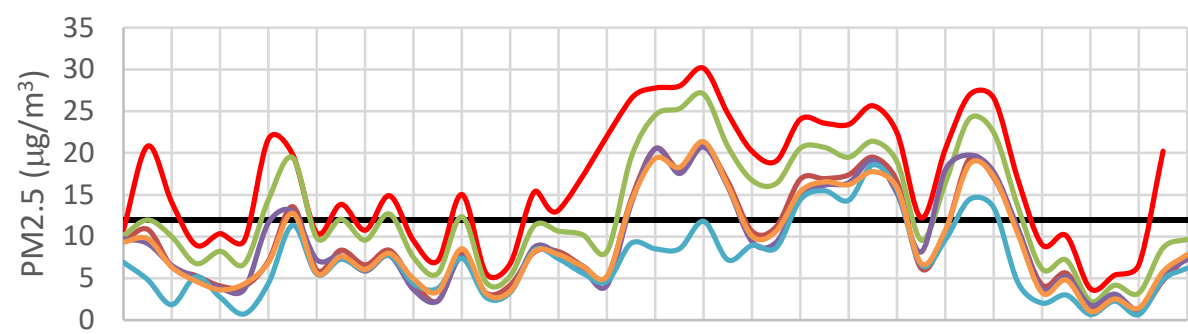

- Threshold 1

- Outside location

- Office 012

- Registry

— Office 104

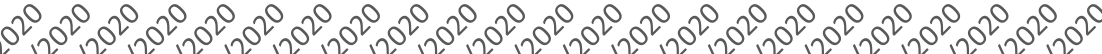

- Office 223

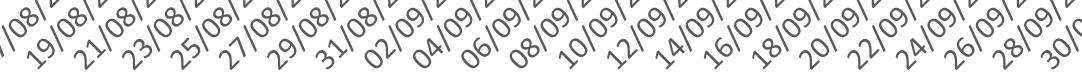

$\mathrm{CO}_{2}$ daily average values

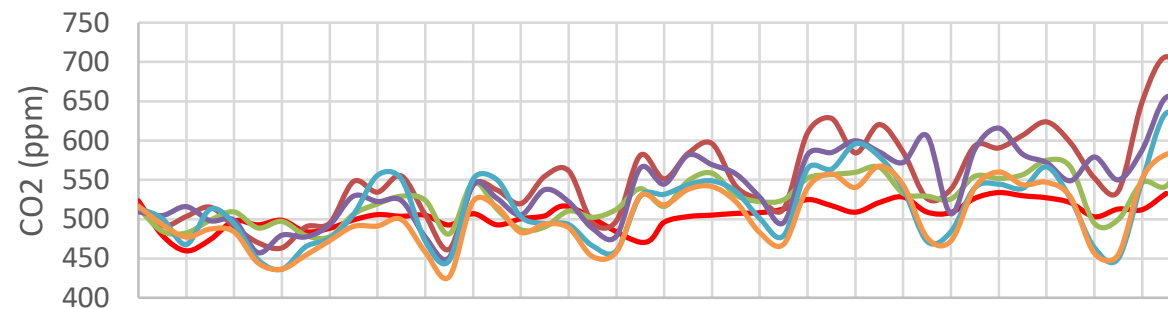

- Outside location

— Office 012

Registry

—_ Office 104

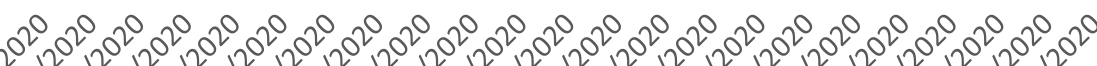

Office 223

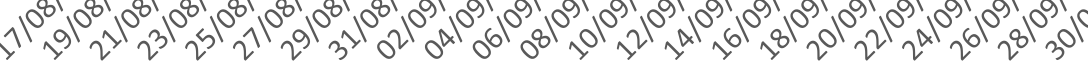

Temperature daily average values

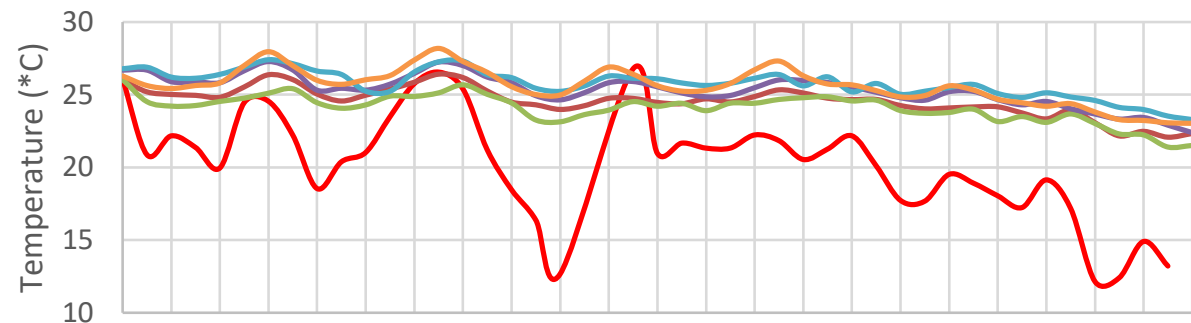

- Outside location

— Office 012

Registry

— Office 104

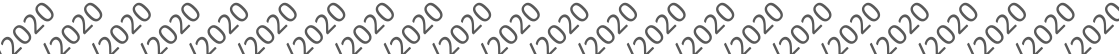

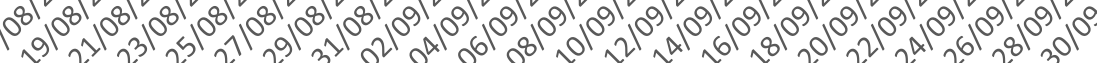

Humidity daily average values

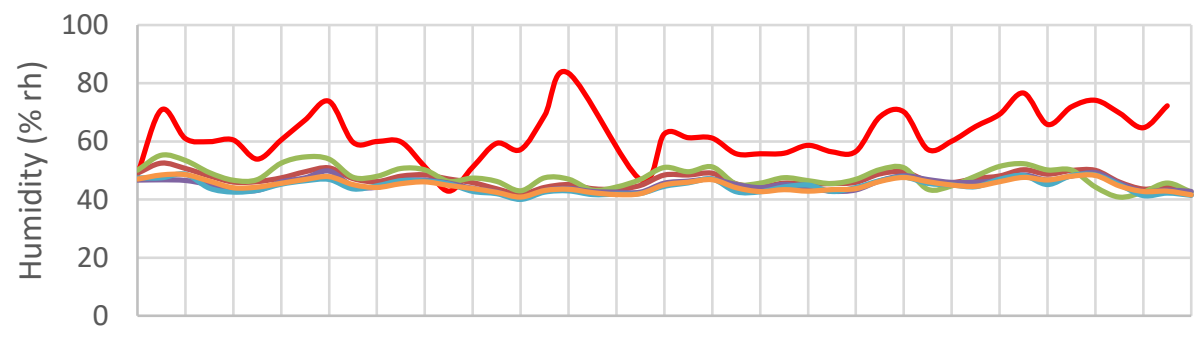

- Outside location

- Office 012

- Registry

— Office 104

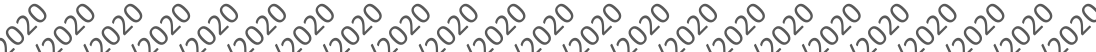

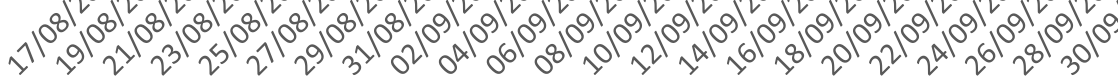

Fig. 2. Results of the campaign from 17/OCT/2020 till 30/SEP/2020 


\section{Conclusion}

New method for real-time air quality monitoring is presented. It is based on modern cloud system for measurements of air quality parameters. Set of 10 sensors for PM concentration, $\mathrm{CO}_{2}$, temperature and humidity was assembled and calibrated in the laboratory. Measurements were performed in a modern business building, showing the capabilities of this system. Test period of 45 days was completely successful, which gave clear answer to our research question: this system can be used for indoor air quality monitoring and management, not only in small laboratories, but also in very large buildings.

In the future work this project should be scaled to many sensors in different buildings. Possible future applications are: air quality monitoring in kindergartens, schools, universities, industrial production workplaces etc.

\section{References}

[1] Neethirajan, S., Jayas, D. S. \& Sadistap, S. (2009). Carbon dioxide (CO2) sensors for the agri-food industry - a review. Food and Bioprocess Technology, 2:115-121, 2009, DOI: 10.1007/s11947-008-0154-y

[2] Mendes, L. B. et al. (2015). NDIR Gas Sensor for Spatial Monitoring of Carbon Dioxide Concentrations in Naturally Ventilated Livestock Buildings, Sensors, 15, 11239-11257, 2015, DOI: 10.3390/s150511239

[3] Yasuda, T., Yonemura, S. \& Tani A. (2012). Comparison of the Characteristics of Small Commercial NDIR CO2 Sensor Models and Development of a Portable CO2 Measurement Device, Sensors, 12, 3641-3655, 2012, DOI: $10.3390 / \mathrm{s} 120303641$

[4] Cho, H. C. \& Yi, S. H. (2010). NDIR CO2 gas sensor with improved temperature compensation. Procedia Engineering 5:303-306, 2010, DOI: 10.1016/j.proeng.2010.09.108

[5] Kim, J.H., Park H. G. \& Yi S. H. (2018). IR Absorbance as a Criterion for Temperature Compensation in Nondispersive Infrared Gas Sensor. Proceedings. 2018, DOI: 10.3390/proceedings2130775

[6] Masic, A.; Bibic, D. \& Pikula, B. (2019). On the applicability of low-cost sensors for measurements of aerosol concentrations, Proceedings of the 30th DAAAM International Symposium, pp.0452-0456, B. Katalinic (Ed.), Published by DAAAM International, ISBN 978-3-902734-22-8, ISSN 1726-9679, Vienna, Austria DOI: 10.2507/30th.daaam.proceedings.060

[7] Masic. A.; Bibic, D.; Pikula, B.; Blazevic, A.; Huremovic, J. \& Zero, S. (2020). Evaluation of optical particulate matter sensors under realistic conditions of strong and mild urban pollution. Atmospheric Measurement Techniques, Preprint, DOI: 10.5194/amt-2020-237

[8] Masic, A[dnan]; Bibic, D[zevad]; Pikula, B[oran] \& Razic, F[aruk] (2018). New approach of measuring toxic gases concentrations: principle of operation, Proceedings of the 29th DAAAM International Symposium, pp.0882-0887, B. Katalinic (Ed.), Published by DAAAM International, ISBN 978-3-902734-20-4, ISSN 1726-9679, Vienna, Austria, DOI: 10.2507/29th.daaam.proceedings.127

[9] Bibic, D[zevad]; Pikula, B[oran]; Masic, A[dnan] \& Razic, F[aruk] (2018). New approach of measuring toxic gases concentrations: application examples, Proceedings of the 29th DAAAM International Symposium, pp.0876-0881, B. Katalinic (Ed.), Published by DAAAM International, ISBN 978-3-902734-20-4, ISSN 1726-9679, Vienna, Austria, DOI: 10.2507/29th.daaam.proceedings.126

[10] Masic. A.; Bibic, D.; Pikula, B.; Dzaferovic-Masic, E. \& Musemic, R. (2019). Experimental study of temperature inversions above urban area using unmanned aerial vehicle. Thermal Science, Vol. 23, No. 6A, pp. 3327-3338, DOI: 10.2298/TSCI180227250M 